\title{
Correction to: Epidemiological and clinical characteristics of the first 500 confirmed COVID-19 inpatients in a tertiary infectious disease referral hospital in Manila, Philippines
}

Kristal An Agrupis ${ }^{1,2}$, Chris Smith ${ }^{1,3^{*}}$, Shuichi Suzuki ${ }^{1,2}$, Annavi Marie Villanueva ${ }^{1,4}$, Koya Ariyoshi $^{5}$, Rontgene Solante ${ }^{4}$, Elizabeth Freda Telan ${ }^{4}$, Kelly Anne Estrada ${ }^{4}$, Ann Celestyn Uichanco ${ }^{4}$, Jocelyn Sagurit ${ }^{4}$, Joy Calayo ${ }^{4}$, Dorcas Umipig ${ }^{4}$, Zita dela Merced ${ }^{4}$, Fe Villarama ${ }^{4}$, Efren Dimaano ${ }^{4}$, Jose Benito Villarama ${ }^{4}$, Edmundo Lopez ${ }^{4}$ and Ana Ria Sayo ${ }^{4}$

Correction to: Trop Med Health 49, 48 (2021) https://doi.org/10.1186/s41182-021-00340-0

Following publication of the original article [1], a funding information was missing in the Funding section.

The updated Funding section is given below and the changes have been highlighted in bold typeface.

\section{Funding}

This work is in part funded by Nagasaki University (salary support for CS, KAA, and SS). This study is partially funded by Japan Agency for Medical Research and Development, Grant/Award Numbers: JP19fk0108104h0401, JP20fk0108104h0402.

The original article [1] has been corrected.

\section{Author details}

${ }^{1}$ School of Tropical Medicine and Global Health, Nagasaki University, Nagasaki, Japan. ${ }^{2}$ San Lazaro Hospital-Nagasaki University Collaborative Research Office, Manila, Philippines. ${ }^{3}$ Department of Clinical Research, London School of Hygiene and Tropical Medicine, London, UK. ${ }^{4}$ San Lazaro Hospital, Manila, Philippines. ${ }^{5}$ Institute of Tropical Medicine, Nagasaki University, Nagasaki, Japan.
Published online: 13 July 2021

\section{Reference}

1. Agrupis, et al. Epidemiological and clinical characteristics of the first 500 confirmed COVID-19 inpatients in a tertiary infectious disease referral hospital in Manila, Philippines. Trop Med Health. 2021;49:48.

The original article can be found online at https://doi.org/10.1186/s41182021-00340-0.

* Correspondence: christopher.smith@lshtm.ac.uk

'School of Tropical Medicine and Global Health, Nagasaki University,

Nagasaki, Japan

${ }^{3}$ Department of Clinical Research, London School of Hygiene and Tropical

Medicine, London, UK

Full list of author information is available at the end of the article

(c) The Author(s). 2021 Open Access This article is licensed under a Creative Commons Attribution 4.0 International License, which permits use, sharing, adaptation, distribution and reproduction in any medium or format, as long as you give appropriate credit to the original author(s) and the source, provide a link to the Creative Commons licence, and indicate if changes were made. The images or other third party material in this article are included in the article's Creative Commons licence, unless indicated otherwise in a credit line to the material. If material is not included in the article's Creative Commons licence and your intended use is not permitted by statutory regulation or exceeds the permitted use, you will need to obtain permission directly from the copyright holder. To view a copy of this licence, visit http://creativecommons.org/licenses/by/4.0/. 